\title{
EFEKTIVITAS TUGAS DOSEN PENASEHAT AKADEMIK DENGAN DIBERLAKUKANNYA SISTEM KRS ONLINE PADA MAHASISWA JURUSAN TEKNIK MESIN FT-UNP
}

\section{THE EFFETIVINESS OF THE TASK LECTURESS ACADEMI ADVISORS WITH IMPLEMENTED THE SYSTEM OF KRS ONLINE ON A STUDENT MAJORING IN MECHANICAL ENGINEERING FT-UNP}

\author{
Miftahul Fikri ${ }^{(1)}$, Nelvi Erizon ${ }^{(2)}$ Jasman $^{(3)}$ Purwantono $^{(4)}$ \\ (1), (2), (3), (4) Jurusan Teknik Mesin, Fakultas Teknik, Universitas Negeri Padang \\ Kampus Air Tawar, Padang 25131, Indonesia \\ miftahulfikrimsn@gmail.com \\ nelvierizon@yahoo.com \\ jasmanmesin@yahoo.com
}

\begin{abstract}
Abstrak
Penelitian ini berawal dari masalah tugas dosen penasehat akademik dengan diberlakukannya sistem KRS online yang mana sebagian mahasiswa merasa asing bahkan tidak mengenal dosen PA-nya sendiri, karena mahasiswa tidak memiliki motivasi yang kuat untuk mengenal dan memahami tugas serta tanggung jawab dosen PA. Melihat masalah tersebut, maka dilakukan penelitian bertujuan untuk mengetahui seberapa efektif tugas dosen penasehat akademik dengan diberlakukanya sistem KRS Online. Penelitian ini merupakan penelitian deskriftif kuantitatif dengan jumlah populasi sebanyak 146 orang mahasiswa tahun masuk 2013. Dengan jumlah sampel sebayak 59 orang mahasiswa, sampel diambil dengan menggunakan teknik Proporsionale random Sampling. Jenis data yang digunakan dalam penelitian ini adalah data primer. Data primer dikumpulkan menggunakan angket dengan skala likert yang menggunakan 5 pilihan jawaban, yang terdiri dari pernyataan positif dan negatif. Jumlah pernyataan dalam angket sebanyak 37 butir pernyataan. Hasil penelitian ini menunjukkan bahwa Indikator bimbingan akademik berada pada kategori Baik terhadap efektivitas tugas dosen penasehat akademik dengan diberlakukanya sistem KRS online yaitu 3,08. Indikator bimbingan non akademik berada pada kategori Baik terhadap efektivitas tugas dosen penasehat akademik dengan diberlakukanya sistem KRS online yaitu 3,10 dan untuk Indikator memberikan bantuan untuk mencapai prestasi yang optimal kategori Baik terhadap efektivitas tugas dosen penasehat akademik dengan diberlakukanya sistem KRS online yaitu 3.13.
\end{abstract}

Kata Kunci : Efektivitas, Dosen Penasehat, Akademik, Mahasiswa, KRS Online

\begin{abstract}
This research is beginning from the task of lecturers academic advisors problems with implementation the system of KRS online where most student the feel foreign do not even know of lecturers academic advisors his own, because student do not have a strong motivation to get to know and understand the duties and responsibilities of the task of lecturers academic advisors. Seeing the problem, the research aims to find out how effective the task of lecturers academic advisors with implemented the the system of KRS Online.This research is descriptive quantitative with a total population of 146 student the entry year 2013. With a total sample of 59 student, a sample taken by using proporsionale random sampling. Type of data used in this study are primary data. The primary data was collected using a questionnaire with a Likert scale that uses 5 answer choices, which consists of positive and negative statements. The number of statements in the questionnaire as much as 37 point statement.The results of this research showed that the academic guidance indicators that are in the category of Good on the the effectiveness of the task of lecturers academic advisors with implemented the system of KRS online is 3.08. Non-academic guidance indicators that are in the category of Good of the effectiveness of the task of lecturers academic advisors with implemented the system of KRS online is 3.10 and for the Indicators provide assistance to achievement the optimal category Good on the effectiveness of the task of lecturers academic advisors with implemented the system of KRS onlineis 3.13.
\end{abstract}

Keywords : Effectiveness, Lecturers Academic, Advisors,Student, KRS Online 


\section{A. Pendahuluan}

Perguruan tinggi merupakan salah satu lembaga pendidikan yang diharapkan dapat merealisasikan dan mewujudkan suatu tujuan pendidikan nasional. Perguruan tinggi diharapkan mampu menunjang peningkatan kualitas dan mutu pendidikan.

Prestasi belajar mahasiswa sangat ditentukan oleh berbagai faktor. Secara garis besar faktor tersebut terbagi dalam faktor internal atau faktor dalam diri dan faktor eksternal atau faktor luar diri. Faktor dari dalam diri misalnya minat, kecerdasan, bakat, dan sebagainya. Faktor dari luar diri misalnya lingkungan, fasilitas, dosen atau di sebut juga sebagai penasehat akademik. Dari beberapa faktor tersebut yang di duga sebagai salah satu penyebab rendahnya hasil belajar mahasiswa yaitu kurangnya bimbingan dari dosen pembimbing akademik, tetapi kurangnya bimbingan dari pembimbing akademik bukan karena dosenya yang tidak bisa membimbing, melainkan karena mahasiswanya yang jarang bahkan tidak pernah menemui pembimbing akademiknya.

Pembimbing Akademik (yang selanjutnya di singkat dengan PA) adalah orang yang paling tepat untuk menjadi sumber bantuan nasehat akademik dan non akademik serta tempat mahasiswa dalam memecahkan kesulitan baik dalam kegiatan belajar maupun kegiatan lainya agar para mahasiswa dapat menyelesaikan tugasnya sebagai mahasiswa.

Dosen PA kurang memberikan respon pada mahasiswa yang tidak mendatanginya untuk berkonsultasi tentang penyusunsan rencana program perkuliahan. Selain itu dosen PA jarang mengikuti bagaimana perkembangan studi mahasiswa, menanyakan mengapa indeks prestasi yang di caapai mahasiswa rendah, adakah masalah yang dihadapi, baik masalah akademik maupun non akademik. Hal ini mungkin terjadi karena kesibukan mengajar dan tugas lainya sehingga mengakibatkan dosen PA kurang memahami dan kurang memberikan perhatian yang serius terhadap mahasiswanya. Dalam pelaksanaan sistem kredit semester (SKS) di UNP, setiap mahasiswa diberi kebebasan untuk memilih serta menetapkan mata kuliah yang ingin di ambilnya. Kebebasan tersebut akan berdampak positif apabila setiap mahasiswa memiliki informasi yang tepat dan mengerti tentang tata aturan sistem kredit yang di ikuti.

Kenyataan yang dihadapi saat ini, mahasiswa lebih cenderung memilih, menetapkan, dan menyusun rencana program perkuliahan sendiri tanpa adanya konsultasi terlebih dahulu dengan dosen PA. Apalagi semenjak di berlakukanya KRS Online di UNP peranan dosen PA semakin hilang, karena mahasiswa bisa langsung melakukan registrasi untuk penetapan KRS tanpa adanya konsultasi terlebih dahulu dengan dosen PA. Dosen PA saat ini hanya di manfaatkan mahasiswa pada saat membutuhkan tanda tangan saja, seperti pada waktu untuk Pengesahan Kartu rencana Studi (KRS). Bila tugas dosen PA dalam sistem KRS Online dapat di optimalkan pelaksanaannya, di samping itu juga diharapkan dapat meningkatkan hasil belajar mahasiswa.

\section{B. Metode Penelitian}

\section{Jenis Penelitian}

Penelitian ini merupakan penelitian deskriptif kuantitatif yang mendeskripsikan Efektifitas Tugas Dosen Penasehat Akademik dengan Diberlakukanya Sistem KRS Online pada Mahasiswa Jurusan Teknik Mesin FT-UNP yang diteliti melalui populasi sebagaimana adanya. Menurut Cholid Narbuko \& Abu Achmadi (2008:44) metode deskriptif kuantitatif yaitu penelitian yang berusaha untuk menuturkan pemecahan masalah yang ada sekarang berdasarkan data-data dengan menggambarkan keadaan objek penelitian berdasarkan fakta-fakta yang tampak sebagaimana adanya dengan penyelidikan ilmiah, sistematis dan terarah.

Sehubungan dengan pendapat di atas, penelitian ini bertujuan untuk mengetahui "Efektivitas Tugas Dosen Penasehat Akademik dengan Diberlakukanya Sistem KRS Online pada Mahasiswa Jurusan Teknik Mesin FT-UNP”.

\section{Tempat dan Waktu Penelitian}

Penelitian ini dilakukan di Jurusan Teknik Mesin FTUNP, yang berlangsung mulai bulan Juli 2016 sampai januari 2017.

\section{Populasi dan Sampel}

\section{a. Populasi}

Populasi adalah keseluruhan dari objek penelitian atau penyelidikan baik berupa karakteristik nilainilai, jumlah maupun jenis dari objek tersebut. Suharsimi Arikunto dalam Kusrini (2005: 28) menjelaskan bahwa "Populasi adalah seluruh data yang menjadi perhatian kita dalam satu ruang lingkup dan waktu yang kita tentukan. Jadi populasi berhubungan dengan data, banyak dan manusia. Kalau setiap manusia memberikan suatu data, maka banyaknya atau ukuran populasi akan sama dengan banyak manusia".

Kata berimbang menunjuk pada ukuran jumlah yang tidak sama, disesuaikan dengan jumlah anggota tiaptiap kelompok yang lebih besar. Dengan pengertian itu maka dalam menentukan anggota sampel, peneliti mengambil wakil-wakil dari tiap kelompok yang ada dalam populasi yang jumlahnya disesuaikan dengan jumlah anggota subjek yang ada di dalam masingmasing kelompok tersebut.

Dari kutipan di atas jelas bahwa populasi adalah keseluruhan dari objek yang diteliti, sehingga yang dijadikan populasi dalam penelitian ini adalah mahasiswa tahun masuk 2013. Untuk lebih jelasnya 
perincian populasi dapat dilihat pada tabel di bawah ini.

Tabel 1. Jumlah Mahasiswa Angkatan 2013 Jurusan Teknik Mesin sebagai Populasi

\begin{tabular}{|l|l|l|}
\hline No & Tahun Masuk 2013 & Jumlah Populasi \\
\hline 1 & S1 & 85 Orang \\
\hline 2 & D3 & 61 Orang \\
\hline \multicolumn{2}{|l}{ Jumlah } & 146 Orang \\
\hline
\end{tabular}

Sumber : Jurusan Teknik Mesin

\section{b. Sampel}

Suharsimi (2010: 174) menyatakan "Sampel adalah sebagian atau wakil populasi yang diteliti”. Dari seluruh populasi yang ada sebanyak 102 orang siswa maka teknik pengambilan sampel menggunakan rumus dari Riduwan (2006: 65) sebagai berikut:

$$
n=\frac{\mathrm{N}}{\mathrm{N} \cdot d^{2}+1}
$$

Dimana:

$\mathrm{n}=$ Jumlah sampel

$\mathrm{N}=$ Jumlah populasi

$\mathrm{d}^{2}=$ Presisi yang ditetapkan sebesar 5\%

berdasarkan rumus di atas, maka jumlah sampel dalam penelitian ini adalah :

$$
\mathrm{n}=\frac{146}{146 \cdot 0,1^{2}+1}=59 \text { orang }
$$

Sampel ditentukan oleh teknik sampling berimbang (Proportional Sampling). Suharsimi Arikunto(2010:98) mengatakan:

Penelitian menggunakan teknik ini karena sampel yang akan diteliti adalah mahasiswa Jurusan Teknik Mesin UNP Prodi S1 dan D3 tahun masuk 2013, sehingga sampel penelitian harus diambil dari perwakilan tahun masuk mahasiswa. Penetapan sampel masing-masing program studi dilakukan dengan teknik proportionale random sampling menggunakan rumus Sugiyono, dalam Riduwan (2013:66) sebagai berikut:

Dimana:

$$
n i=\frac{N_{i}}{N} \mathrm{x} n
$$

ni $=$ jumlah sampel menurut stratum

$\mathrm{n}=$ jumlah sampel seluruhnya

$N_{i}=$ jumlah populasi menurut stratum

$N=$ jumlah populasi seluruhnya

Berdasarkan rumus tersebut diperoleh jumlah sampel menurut angkatan sebagai berikut:

n S1 $=(85 / 146)$ x 59=34,34 ${ }^{\approx} 34$ mahasiswa

$\mathrm{n} \mathrm{D} 3=(61 / 146) \times 59=24,65 \approx 25$ mahasiswa

Untuk lebih jelas jumlah sampel pada masing-masing angkatan mahasiswa dapat dilihat pada tabel 3 berikut :
Tabel 2. Jumlah Sampel Penelitian

\begin{tabular}{|l|l|l|l|}
\hline No & $\begin{array}{l}\text { Tahun } \\
\text { Masuk } \\
2013\end{array}$ & $\begin{array}{l}\text { Jumlah } \\
\text { Populasi }\end{array}$ & $\begin{array}{l}\text { Jumlah } \\
\text { Sampel }\end{array}$ \\
\hline 1 & S1 & 85 orang & 34 orang \\
\hline 2 & D3 & 61 orang & 25 orang \\
\hline \multicolumn{2}{|l}{ Jumlah } & 146 orang & 59 orang \\
\hline
\end{tabular}

Sumber : Jurusan Teknik Mesin

\section{Variabel dan Data Penelitian}

a. Variabel Penelitian

Dalam penelitian ini hanya ada satu variabel yang diteliti, yaitu Efektifitas Tugas Dosen Penasehat Akademik dalam Diberlakukanya Sistem KRS Online pada Mahasiswa Jurusan Teknik Mesin FTUNP.

\section{b. Data Penelitian}

Data penelitian ini bersumber dari responden secara langsung. Diperoleh dari jawaban responden pada angket yang diberikan, dan pengamatan langsung dilapangan.

\section{Instrumen Penelitian}

a. Jenis dan Alat Pengumpulan Data

Teknik pengumpulan data dilakukan dengan mengisi angket. Angket adalah alat pengumpul data berupa serangkaian pertanyaan yang diajukan kepada objek (responden) penelitian untuk mendapat jawaban tentang apa yang ingin diketahui.

Jenis angket yang digunakan adalah angket tertutup yaitu angket yang disajikan dalam bentuk sedemikian rupa sehingga responden tinggal memberikan tanda centang (v) pada kolom atau tempat yang sesuai. Pemilihan jenis angket ini disesuaikan dengan pertanyaan yang akan diajukan guna menggali informasi dan memperoleh data dari responden.

\section{b. Penyusunan Instrumen Penelitian}

Dalam penyusunan instrument tersebut dilakukan beberapa tahap, yaitu (a) pembuatan kisi-kisi, (b) pembuatan butir-butir pertanyaan, (c) melakukan uji coba dan (d) melakukan analisis, (e) melakukan penelitian. Uji coba dilakukan kepada mahasiswa jurusan Teknik Mesin angkatan 2013 di luar sampel yang dipilih dengan acak random. Instrumen yang digunakan pada penelitian ini adalah angket (kuisioner) berisi jumlah pertanyaan tertulis yang digunakan untuk memperoleh informasi dari responden, dan untuk menapatkan hasil dengan menggunakan skala likert.

Tabel 3. Skala Likert

\begin{tabular}{|c|c|}
\hline $\begin{array}{c}\text { Pernyataan } \\
\text { positif }\end{array}$ & $\begin{array}{c}\text { Pernyataan } \\
\text { negatif }\end{array}$ \\
\hline
\end{tabular}




\begin{tabular}{|l|l|}
\hline $5=\mathrm{SL}$ & $1=\mathrm{SL}$ \\
\hline $4=\mathrm{SR}$ & $2=\mathrm{SR}$ \\
\hline $3=\mathrm{KD}$ & $3=\mathrm{KD}$ \\
\hline $2=\mathrm{JR}$ & $4=\mathrm{JR}$ \\
\hline $1=\mathrm{TP}$ & $5=\mathrm{TP}$ \\
\hline
\end{tabular}

Sumber: Sugiyono (2013: 108)

Ket $: \mathrm{SL}=$ Selalu, $\mathrm{SR}=$ Sering, $\mathrm{KD}=$ Kadang-kadang, $\mathrm{JR}=\mathrm{Jarang}, \mathrm{TP}=$ Tidak Pernah

Dalam penyusunan item untuk setiap indikator, peneliti mengusahakan semaksimal mungkin agar item-itemnya dapat mengukur apa yang hendak diteliti dan berkaitan erat dengan sub indikator variabelnya.

Tabel 4. Kisi- kisi Rancangan Instrumen Uji Coba Penelitian

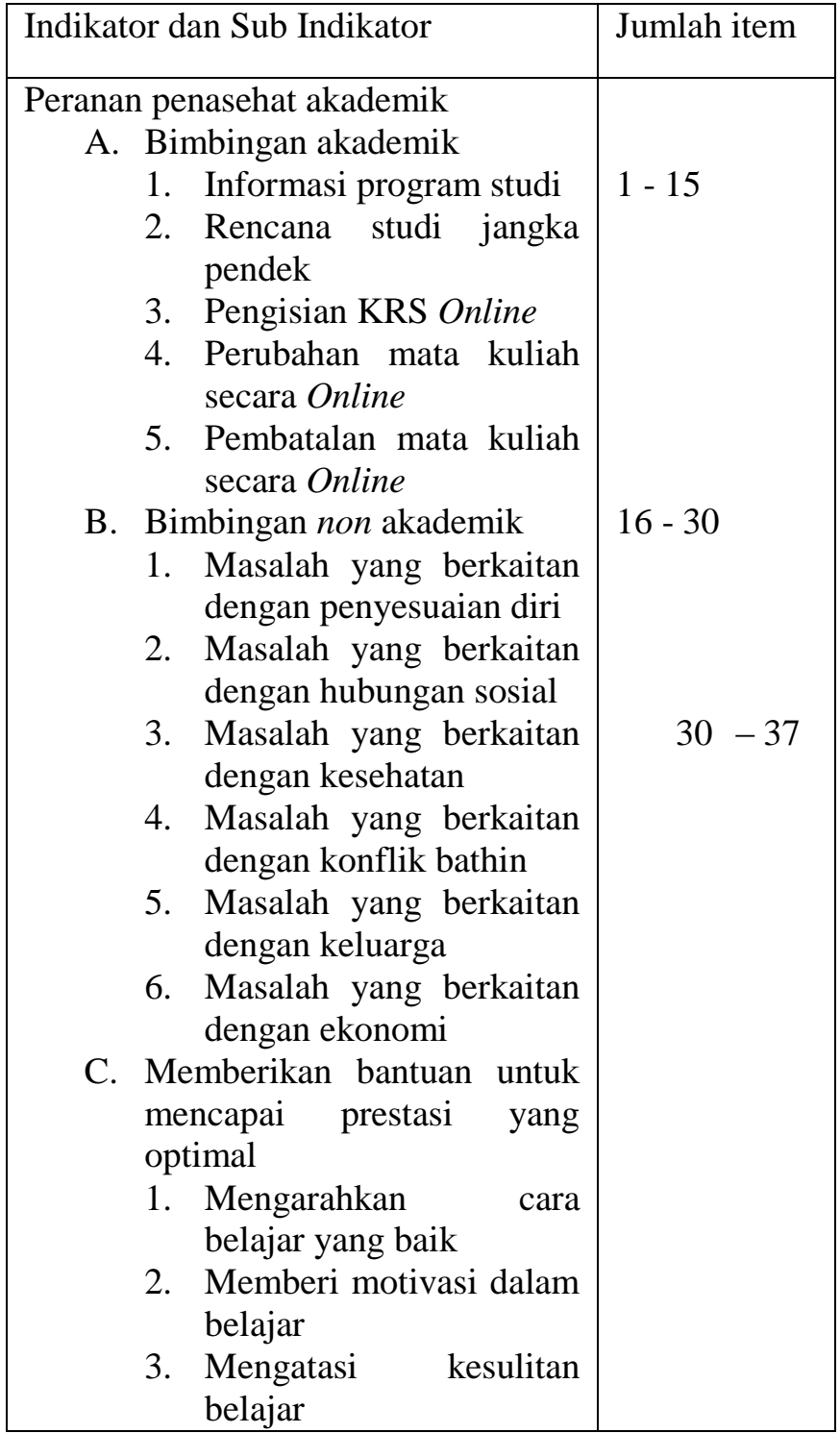

\section{c. Uji Coba Instrumen}

Uji coba instrumen dilakukan diluar sampel penelitian dengan berjumlah 30 orang tetapi memiliki kriteria yang sama dengan sampel penelitian ini. Responden yang dipakai dalam uji coba kuesioner diambil secara acak sebagaimana ketentuan-ketentuan yang sesuai dengan penelitian sebenarnya.

\section{d. Analisis Item}

1) Uji Validitas

Suharsimi Arikunto (2010:75) mengartikan validitas sebagai ketepatan. Validitas terkait dengan ketepatan objek yang tidak lain adalah tidak menyimpangnya data dari kenyataan artinya bahwa data tersebut benar. Sebuah tes yang baik adalah jika tes tersebut memiliki validitas yang tinggi. Untuk mengetahui validitas sebuah tes maka digunakan rumus korelasi product moment, yaitu:

$$
r \mathrm{xy}=\frac{\mathrm{N} \sum \mathrm{XY}-\left(\sum \mathrm{X}\right)\left(\sum \mathrm{Y}\right)}{\sqrt{\left\{N \sum X^{2}-\left(\sum X\right)^{2}\right\}}\left\{N \sum Y^{2}-\left(\sum Y\right)^{2}\right\}}
$$

Dengan keterangan:

rxy : validitas butir soal/item

$\mathrm{N}$ : jumlah siswa peserta tes

$\mathrm{X} \quad$ : skor butir soal/item

$\mathrm{Y} \quad$ : skor total

Setelah melakukan uji coba instrumen kepada 30 mahasiswa dengan 40 item pernyataan, maka dilakukan penganalisisan data validasi dengan menggunakan microsof office (Excel), terdapat 3 butir penyataan yang tidak valid. Hal ini dibuktikan pada tabel di bawah ini:

Tabel 5. Butir Pernyataan yang tidak Valid

\begin{tabular}{|l|l|l|}
\hline No & $\begin{array}{l}\text { Butir Yang } \\
\text { Tidak Valid }\end{array}$ & $\begin{array}{l}\text { Keterangan }(\mathrm{r} \text { Hitung }<\quad r \\
\text { Tabel) }\end{array}$ \\
\hline 1 & Butir 24 & $-0,29<0,361$ \\
\hline 2 & Butir 28 & $0,342<0,361$ \\
\hline 3 & Butir 40 & $0,273<0,361$ \\
\hline
\end{tabular}

Instrumen penelitian dengan item pernyataan sebanyak 37 butir valid untuk dilanjutkan.

2) Uji Reliabilitas

Anas Sudijono (2011:95) mengartikan kata reliabilitas sering diterjemahkan dengan keajegan (stability) atau kemantapan (consistency).

Untuk menghitung reliabilitas digunakan rumus KR21 dalam Anas Sudijono (2011:258) sebagai berikut:

$$
r 11=\left(\frac{n}{n-1}\right)\left(1-\frac{M t(n-M t)}{(n)\left(S t^{2}\right)}\right)
$$

Dengan keterangan:

r11 : reliabilitas tes secara keseluruhan

n : banyaknya butir soal tes

Mt : jumlah nilai skor total siswa dibagi jumlah seluruh siswa $\left(\sum \mathrm{Xt} / \mathrm{N}\right)$

$\mathrm{St}^{2} \quad$ : standar deviasi dari tes

Hasil analisis uji coba instrumen microsof office excle diperoleh tingkat reliabel 0,885 . Tingkat reliabelitas termasuk kategori sangat baik. 


\section{Teknik Analisis Data}

Adapun langkah-langkah yang dilakukan adalah sebagai berikut :

a. Memeriksa semua angket yang telah diisi oleh mahasiswa jurusan Teknik Mesin FT-UNP angkatan 2013.

b. Membuat tabel persiapan untuk tabulasi data.

c. Menghitung frekuensi dari setiap alternatif jawaban yang diberikan.

d. Menghitung persentase jawaban dengan rumus :

$$
\mathrm{P}=\frac{f}{N} \times 100
$$

Keterangan : $\quad \mathrm{P}=$ Persentase yang dicari

$\mathrm{F}=$ Frekuensi jumlah skor

$\mathrm{N}=$ Total jumlah responden

e. Selanjutnya untuk memberikan interpretasi pada persentase yang telah diperoleh, dihitung dengan menggunakan rumus rata-rata (mean) oleh Nana Sudjana (2002:125):

$$
\mathrm{M}=\frac{\sum(F i . X i)}{\sum F i}
$$

Keterangan : $\quad \mathrm{M}=$ mean yang dicari

$\Sigma f i=$ jumlah frekuensi jawaban

$\mathrm{Fi}=$ Frekuensi jawaban

$\mathrm{Xi}=$ Skor pilihan jawaban

Harga mean yang telah diperoleh dari hasil perhitungan di atas, dapat dikonsultasikan dengan tabel berikut:

Tabel 6. Harga Mean Tabel

\begin{tabular}{|l|l|l|}
\hline No & Nilai Mean & Kategori \\
\hline 1 & $3,76-5,00$ & Sangat Baik \\
\hline 2 & $2,50-3,75$ & Baik \\
\hline 3 & $1,26-2,50$ & Kurang Baik \\
\hline 4 & $0,00-1,25$ & Tidak Baik \\
\hline
\end{tabular}

Sumber: Sugiyono (2005: 128)

\section{Hasil dan Pembahasan}

\section{Deskripsi Data}

Deskripsi data mengungkapkan informasi tentang nilai rata-rata, median, modus, jumlah skor, standar devisiasi, skor maksimum, skor minimum dengan menggunakan bantuan Microsoft Office Excel.Efektivitas Tugas Dosen Penasehat Akademik dengan Diberlakukannya Sistem KRS Online pada mahasiswa jurusan Teknik Mesin FTUNP dapat di lihat pada tabel di bawah ini.

Tabel 7. Perhitungan Statistik Dasar

\begin{tabular}{|c|c|}
\hline Mean & $\mathbf{3 , 1 6 9}$ \\
\hline Skor Maximum & 5 \\
\hline Skor Minimum & 1 \\
\hline Standar Devisiasi & $\mathbf{0 , 2 1 0}$ \\
\hline
\end{tabular}

\begin{tabular}{|c|c|} 
Mode & $\mathbf{4}$ \\
\hline Median & 4 \\
\hline Sum & $\mathbf{7 3 7 9}$ \\
\hline
\end{tabular}

Data penelitian mengenai peninjauan efektivitas tugas dosen penasehat akademik dengan diberlakukannya sistem KRS online pada mahasiswa jurusan Teknik Mesin FT-UNP, dikumpulkan melalui angket yang terdiri dari 37 butir pernyataan. Angket disebarkan kepada 59 mahasiswa Teknik Mesin FTUNP tahun masuk 2013.

\section{Analisis Data}

a. Indikator Bimbingan Akademik

Efektivitas tugas dosen penasehat akademik dengan diberlakukanya sistem KRS Online pada mahasiswa jurusan Teknik Mesin FT-UNP2013 dengan penyebaran angket yang dijabarkan dalam 15 butir pernyataan. Jumlah subjek yang mengisi angket sebanyak 59 Mahasiswa, maka jawaban untuk 15 butir pernyataan berjumlah 3041 .

Tabel 8. Skor Indikator Jawaban Bimbingan Akademik

\begin{tabular}{|l|l|l|l|l|l|l|}
\hline $\begin{array}{l}\text { Item } \\
\text { pernya } \\
\text { taan }\end{array}$ & $\begin{array}{l}\text { Jenis } \\
\text { pernyata } \\
\text { an }\end{array}$ & SL & SR & KD & JR & TP \\
\cline { 3 - 7 } & Positif & 60 & F & F & F & F \\
\hline 2 & Positif & 70 & 90 & 63 & 6 & 0 \\
\hline 3 & Positif & 40 & 76 & 45 & 28 & 1 \\
\hline 4 & Positif & 55 & 72 & 48 & 16 & 1 \\
\hline 5 & Negatif & 60 & 116 & 33 & 10 & 0 \\
\hline 6 & Positif & 35 & 68 & 63 & 18 & 4 \\
\hline 7 & Positif & 20 & 40 & 93 & 22 & 3 \\
\hline 8 & Negatif & 65 & 60 & 54 & 28 & 0 \\
\hline 9 & Negatif & 65 & 92 & 36 & 10 & 2 \\
\hline 10 & Negatif & 100 & 72 & 27 & 20 & 2 \\
\hline 11 & Negatif & 60 & 108 & 33 & 10 & 0 \\
\hline 12 & Positif & 70 & 102 & 45 & 6 & 1 \\
\hline 13 & Positif & 40 & 132 & 30 & 6 & 0 \\
\hline 14 & Negatif & 25 & 60 & 84 & 20 & 1 \\
\hline 15 & Positif & 25 & 68 & 54 & 32 & 0 \\
\hline
\end{tabular}

Tabel 9. Persentase Jawaban bimbingan Akademik 


\begin{tabular}{|c|c|c|c|c|c|c|}
\hline \multirow[t]{2}{*}{$\begin{array}{l}\mathbf{N} \\
\mathbf{0}\end{array}$} & \multirow[t]{2}{*}{$\begin{array}{l}\text { Option } \\
\text { Jawaban }\end{array}$} & \multicolumn{2}{|c|}{$\begin{array}{l}\text { Skor } \\
\text { Jawaban }\end{array}$} & \multicolumn{2}{|c|}{$\begin{array}{l}\text { Frekuens } \\
\text { i } \\
\text { Jawaban }\end{array}$} & \multirow[t]{2}{*}{$\begin{array}{l}\text { \% } \\
\text { Jawaba } \\
\text { n }\end{array}$} \\
\hline & & + & - & + & - & \\
\hline 1 & Selalu & 5 & 1 & 415 & 375 & $25.97 \%$ \\
\hline 2 & Sering & 4 & 2 & 740 & 508 & $41.03 \%$ \\
\hline 3 & $\begin{array}{l}\text { Kadang- } \\
\text { Kadang }\end{array}$ & 3 & 3 & 477 & 267 & $24.46 \%$ \\
\hline 4 & Jarang & 2 & 4 & 144 & 98 & $7.97 \%$ \\
\hline 5 & $\begin{array}{l}\text { Tidak } \\
\text { Pernah }\end{array}$ & 1 & 5 & 12 & 5 & $0.59 \%$ \\
\hline \multicolumn{4}{|c|}{ Jumlah } & \multicolumn{2}{|c|}{3041} & $100 \%$ \\
\hline
\end{tabular}

Berdasarkan tabel di atas dapat disimpulkan bahwa dengan 15 butir pernyataan indikator bimbingan akademik memberikan respon sejumlah $25.97 \%$ Selalu, 41.03\% Sering, $24.46 \%$ Kadang-Kadang,7.97\% Jarang dan $0.59 \%$ tidak pernah. untuk lebih jelas tentang persentase jawaban responden bisa dilihat pada histogram di bawah ini :

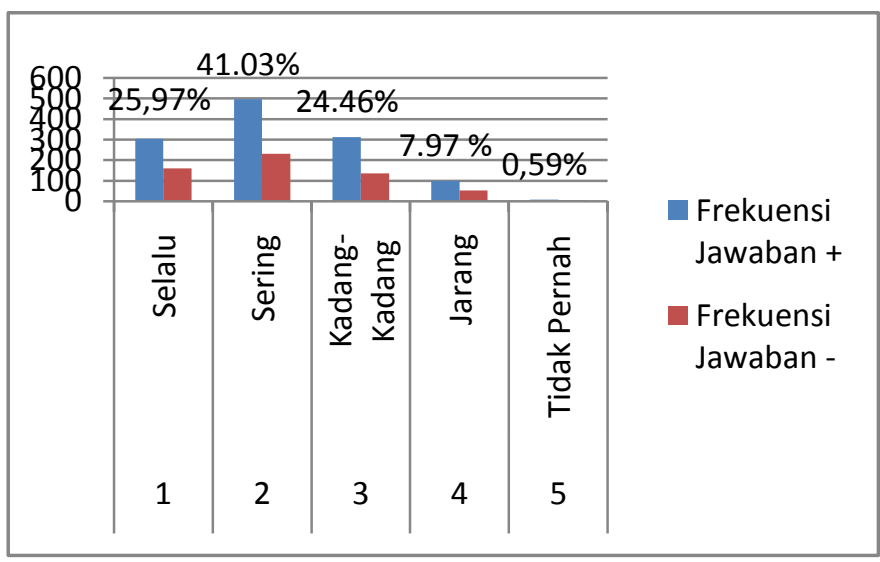

Gambar 1. Histogram Persentase Jawaban Responden Bimbingan Akademik

Skor rata-rata dapat dilihat pada perhitungan nilai mean di bawah ini.

Tabel 10. Perhitungan Nilai Mean bimbingan Akademik

\begin{tabular}{|c|l|l|l|l|l|l|l|}
\hline \multirow{2}{*}{ N } & $\begin{array}{l}\text { Option } \\
\text { Jawaban }\end{array}$ & \multicolumn{2}{|l|}{$\begin{array}{l}\text { Skor } \\
\text { Jawaban }\end{array}$} & \multicolumn{2}{l|}{$\begin{array}{l}\text { Jrekuensi } \\
\text { Jawaban }\end{array}$} \\
\cline { 3 - 8 } & $+f_{i}$. Xi) \\
\hline 1 & Selalu & 5 & 1 & 415 & 37 & 2075 & 375 \\
\hline 2 & Sering & 4 & 2 & 740 & 50 & 2960 & 1016 \\
\hline 3 & Kadang-Kadang & 3 & 3 & 477 & 26 & 1431 & 801 \\
\hline 4 & Jarang & 2 & 4 & 144 & 98 & 288 & 392 \\
\hline 5 & Tidak Pernah & 1 & 5 & 12 & 5 & 12 & 25 \\
\hline Jumlah & & & 3041 & 9375 & \\
\hline
\end{tabular}

Berdasarkan tabel nilai rata-rata indikator bimbingan akademik maka:

$$
\begin{aligned}
\bar{X} & =\frac{\sum(f i . x i)}{\sum f i} \\
& =\frac{9375}{3041}=\mathbf{3 , 0 8}
\end{aligned}
$$

Berdasarkan angka perhitungan di atas dapat diketahui bahwa untuk indikator bimbingan akademik berada pada kategori Baik terhadap efektivitas tugas dosen penasehat akademik dengan diberlakukanya sistem KRS Online yaitu 3,08.

b. Indikator Bimbingan Non akademik

Peninjauan Efektivitas Tugas Dosen Penasehat Akademik Dengan Diberlakukanya Sistem KRS Online pada Mahasiswa Jurusan Teknik Mesin FTUNP 2013dengan penyebaran angket yang dijabarkan dalam 15 butir pernyataan. Jumlah subjek yang mengisi angket sebanyak 59 Mahasiswa, maka jawaban untuk 15 butir pernyataan berjumlah $\mathbf{2 2 8 1}$.

Tarbel 11. Skor Indikator Jawaban Bimbingan Non Akademik

\begin{tabular}{|l|l|l|l|l|l|l|}
\hline \multirow{2}{*}{$\begin{array}{l}\text { Item } \\
\text { pernyata } \\
\text { an }\end{array}$} & $\begin{array}{l}\text { Jenis } \\
\text { pernyata } \\
\text { an }\end{array}$ & F & SR & KD & JR & TP \\
\cline { 3 - 7 } & Positif & 35 & 104 & 42 & F & F \\
\hline 16 & Positif & 24 & 92 & 63 & 12 & 3 \\
\hline 17 & Negatif & 30 & 76 & 63 & 18 & 3 \\
\hline 18 & Positif & 30 & 40 & 72 & 32 & 2 \\
\hline 19 & Positif & 0 & 44 & 84 & 40 & 0 \\
\hline 20 & Negatif & 25 & 56 & 57 & 30 & 0 \\
\hline 21 & Positif & 40 & 116 & 36 & 14 & 1 \\
\hline 22 & Negatif & 25 & 64 & 63 & 24 & 0 \\
\hline 23 & Positif & 35 & 24 & 36 & 50 & 9 \\
\hline 24 & Negatif & 10 & 64 & 45 & 42 & 4 \\
\hline 25 & Positif & 10 & 56 & 33 & 42 & 7 \\
\hline 26 & Positif & 15 & 56 & 69 & 22 & 5 \\
\hline 27 & Negatif & 30 & 64 & 45 & 22 & 11 \\
\hline 28 & & & & & & \\
\hline
\end{tabular}


Tabel 12. Persentase Jawaban Bimbingan Non Akademik

\begin{tabular}{|l|l|l|l|l|l|l|}
\hline \multirow{2}{*}{ No } & \multirow{2}{*}{$\begin{array}{l}\text { Option } \\
\text { Jawaban }\end{array}$} & \multicolumn{2}{|l|}{$\begin{array}{l}\text { Skor } \\
\text { Jawaban }\end{array}$} & \multicolumn{2}{|l|}{$\begin{array}{l}\text { Frekuensi } \\
\text { Jawaban }\end{array}$} & \multirow{2}{*}{ Jawaban } \\
\cline { 3 - 6 } 1 & Selalu & 5 & 1 & 1 & 120 & $13.54 \%$ \\
\hline 2 & Sering & 4 & 2 & 5 & 324 & $37.53 \%$ \\
\hline 3 & Kadang-Kadang & 3 & 3 & 4 & 273 & $31.03 \%$ \\
\hline 4 & Jarang & 2 & 4 & 2 & 136 & $15.87 \%$ \\
\hline 5 & Tidak Pernah & 1 & 5 & 2 & 18 & $2.01 \%$ \\
\hline Jumlah & & & & $\mathbf{2 2 8 1}$ & $\mathbf{1 0 0 \%}$ \\
\hline
\end{tabular}

Berdasarkan tabel di atas dapat disimpulkan dengan 13 butir pernyataan indikator bimbingan non akademik memberikan respon sejumlah 13,54\% Selalu, 37.53\% Sering, 31.03\% Kadang-Kadang, $15.87 \%$ Jarang dan $2.01 \%$ tidak pernah. untuk lebih jelas tentang persentase jawaban responden bisa dilihat pada histogram di bawah ini.

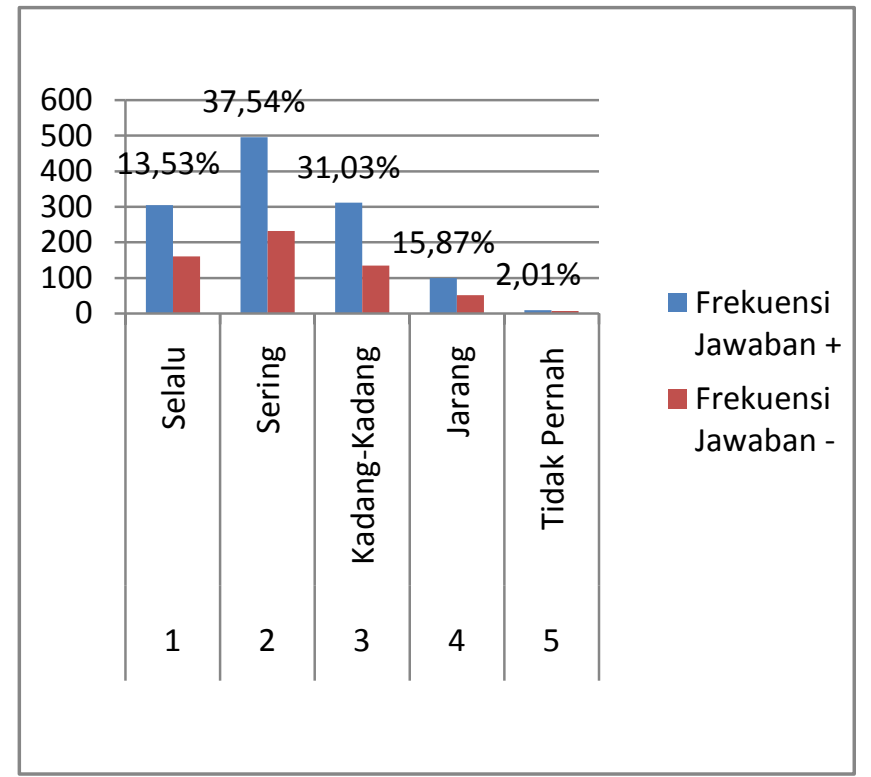

Gambar 2. Histogram Persentase Jawaban Responden Bimbingan Non Akademik

Skor rata-rata dapat dilihat pada perhitungan nilai mean di bawah ini.

Tabel 13. Perhitugan Nilai Mean Bimbingan Non Akademik
Berdasarkan tabel nilai rata-rata indikator bimbingan

\begin{tabular}{|l|l|l|l|l|l|l|l|}
\hline No & \multirow{2}{*}{\begin{tabular}{l} 
Option \\
\multirow{2}{*}{ Jawaban }
\end{tabular}} & \multicolumn{2}{l|}{$\begin{array}{l}\text { Skor } \\
\text { Jawaban }\end{array}$} & \multicolumn{2}{l|}{$\begin{array}{l}\text { Jrekuensi } \\
\text { Jawaban }\end{array}$} & \multicolumn{2}{l|}{$(\mathbf{f i}$ Xi) } \\
\cline { 3 - 8 } & & + & - & + & - & + & - \\
\hline 1 & Selalu & 5 & 1 & 189 & 120 & 945 & 120 \\
\hline 2 & Sering & 4 & 2 & 532 & 324 & 2128 & 648 \\
\hline 3 & Kadang-Kadang & 3 & 3 & 435 & 273 & 1305 & 819 \\
\hline 4 & Jarang & 2 & 4 & 226 & 136 & 452 & 544 \\
\hline 5 & Tidak Pernah & 1 & 5 & 28 & 18 & 28 & 90 \\
\hline Jumlah & & & $\mathbf{2 2 8 1}$ & 7079 & \\
\hline
\end{tabular}

non akademik maka:

$$
\begin{aligned}
\bar{X} & =\frac{\sum(f i . x i)}{\sum f i} \\
& =\frac{\mathbf{7 0 7 9}}{2281}=\mathbf{3 , 1 0}
\end{aligned}
$$

Berdasarkan angka perhitungan di atas dapat diketahui bahwa untukindikator bimbingan non akademikberada pada kategori Baik terhadap efektivitas tugas dosen penasehat akademik dengan diberlakukanya sistem KRS Online yaitu 3,10.

c Indikator Memberikan Bantuan Untuk Mencapai Prestasi Yang Optimal

Peninjauan Efektivitas Tugas Dosen Penasehat Akademik Dengan Diberlakukanya sistem KRS Online pada mahasiswa jurusan Teknik Mesin FTUNP 2013 dengan penyebaran angket yang dijabarkan dalam 15 butir pernyataan. Jumlah subjek yang mengisi angket sebanyak 59 Mahasiswa, maka jawaban untuk 15 butir pernyataan berjumlah.

Tabel 14. Skor Indikator Memberikan Bantuan untuk Mencapai Prestasi yang Optimal

\begin{tabular}{|l|l|l|l|l|l|l|}
\hline \multirow{2}{*}{$\begin{array}{l}\text { Item } \\
\text { pernyataan }\end{array}$} & \multirow{2}{*}{ Jenis pernyataan } & SL & SR & KD & JR & TP \\
\cline { 3 - 7 } & & F & F & F & F & F \\
\hline 29 & Positif & 60 & 96 & 45 & 12 & 1 \\
\hline 30 & Negatif & 55 & 88 & 33 & 12 & 3 \\
\hline 31 & Positif & 55 & 108 & 24 & 12 & 3 \\
\hline 32 & Negatif & 35 & 72 & 51 & 24 & 3 \\
\hline 33 & Positif & 70 & 88 & 51 & 10 & 0 \\
\hline 34 & Positif & 45 & 60 & 75 & 18 & 1 \\
\hline 35 & Negatif & 70 & 72 & 51 & 16 & 1 \\
\hline 36 & Positif & 35 & 100 & 57 & 16 & 0 \\
\hline 37 & Positif & 40 & 44 & 60 & 32 & 4 \\
\hline
\end{tabular}

Tabel 15. Persentase Jawaban Memberikan Bantuan untuk Mencapai Prestasi yang Optimal 
Berdasarkan tabel di atas dapat disimpulkan dengan 9 butir pernyataan, indikator Memberikan Bantuan Untuk Mencapai Prestasi Yang Optimal memberikan respon sejumlah $25.71 \%$ Selalu, $40.26 \%$ Setuju, 24.72\%

\begin{tabular}{|l|l|l|l|l|l|l|}
\hline \multirow{2}{*}{ No } & \multirow{2}{*}{$\begin{array}{l}\text { Option } \\
\text { Jawaban }\end{array}$} & \multicolumn{2}{|l|}{$\begin{array}{l}\text { Skor } \\
\text { Jawaban }\end{array}$} & \multicolumn{2}{l|}{$\begin{array}{l}\text { Jrekuensi } \\
\text { Jawaban }\end{array}$} & \multirow{2}{*}{ Jawaban } \\
\cline { 2 - 6 } & + & - & + & - & \\
\hline 1 & Selalu & 5 & 1 & 305 & 160 & $25.71 \%$ \\
\hline 2 & Sering & 4 & 2 & 496 & 232 & $40.26 \%$ \\
\hline 3 & Kadang-Kadang & 3 & 3 & 312 & 135 & $24.72 \%$ \\
\hline 4 & Jarang & 2 & 4 & 100 & 52 & $8.40 \%$ \\
\hline 5 & Tidak Pernah & 1 & 5 & 9 & 7 & $0.88 \%$ \\
\hline Jumlah & & & $\mathbf{1 8 0 8}$ & $\mathbf{1 0 0 \%}$ \\
\hline
\end{tabular}

sering, 8.40\% Jarang dan 0.88\% Tidak Pernah. untuk lebih jelas tentang persentase jawaban responden bisa dilihat pada histogram di bawah ini.

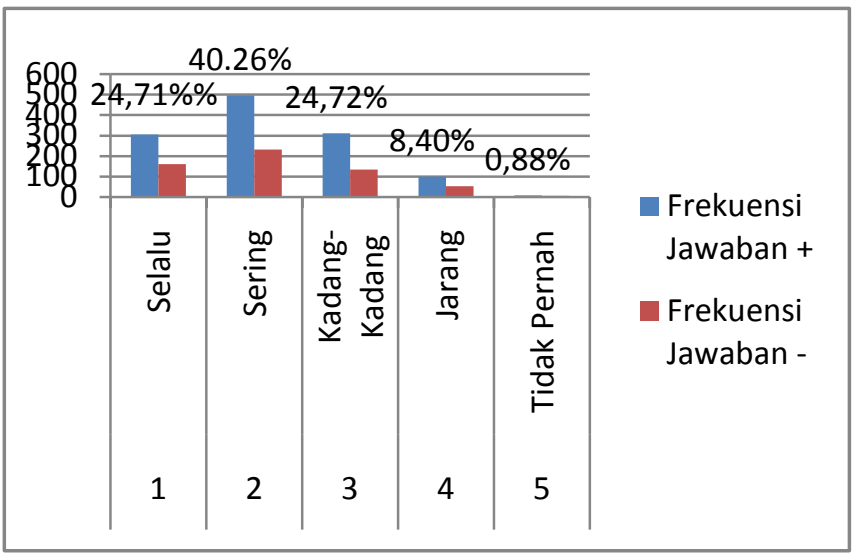

Gambar 3. Histogram Persentase Jawaban Responden Indikator Memberikan Bantuan Untuk Mencapai Prestasi yang Optimal

Skor rata-rata dapat dilihat pada perhitungan nilai mean di bawah ini.

Tabel 16. Perhitungan Nilai Mean Memberikan Bantuan untuk Mencapai Prestasi yang Optimal

\begin{tabular}{|l|l|l|l|l|l|l|l|}
\hline No & $\begin{array}{l}\text { Option } \\
\text { Jawaban }\end{array}$ & $\begin{array}{l}\text { Skor } \\
\text { Jawaba } \\
\text { n }\end{array}$ & \multicolumn{2}{l|}{$\begin{array}{l}\text { Frekuensi } \\
\text { Jawaban }\end{array}$} & \multicolumn{2}{l|}{ (fi . Xi) } \\
\cline { 3 - 9 } & + & - & + & - & + & - \\
\hline 1 & Sangatt Setuju & 5 & 1 & 305 & 160 & 1525 & 160 \\
\hline 2 & Setuju & 4 & 2 & 496 & 232 & 1984 & 464 \\
\hline 4 & Tidak Setuju & 2 & 4 & 312 & 135 & 624 & 540 \\
\hline 5 & $\begin{array}{l}\text { Sangatt Tidak } \\
\text { Setuju }\end{array}$ & 1 & 5 & 100 & 52 & 100 & 260 \\
\hline & & \multicolumn{3}{|c|}{1808} & \multicolumn{3}{|l}{5657} \\
\hline
\end{tabular}

Berdasarkan tabelnilai rata-rata indikator memberikan bantuan untuk mencapai prestasi yang optimal maka:

$$
\begin{aligned}
\bar{X} & =\frac{\sum(f i . x i)}{\sum f i} \\
& =\frac{\mathbf{5 6 5 7}}{\mathbf{1 8 0 8}}=\mathbf{3 , 1 3}
\end{aligned}
$$

Berdasarkan angka perhitungan di atas dapat diketahui bahwa untuk indikator memberikan bantuan untukmencapai prestasi yang optimal berada pada kategori Baik terhadap efektifitas tugas dosen penasehat akademik dengan diberlakukanya sistem KRS Online yaitu 3,13.

Berdasarkan hasil penelitian dari hasil analisis data yang telah dilakukan, maka dapat disimpulkan bahwa indikator bimbingan akademik berada pada kategori baik terhadap efektivitas tugas dosen penasehat akademik dengan diberlakukanya sistem KRS Online yaitu 3,08. sedangkan untuk indikator bimbingan non akademik berada pada kategori baik terhadap efektifitas tugas dosen penasehat akademik dengan diberlakukanya sistem KRS Online yaitu sebesar 3,10.untuk indikator memberikan bantuan untuk mencapai prestasi yang optimal juga berada pada kategori baik terhadap efektifitas tugas dosen penasehat akademik dengan diberlakukanya sistem KRS Online yaitu 3,13.

\section{Kesimpulan}

Berdasarkan hasil penelitian dan hasil analisis data yang telah dilakukan, maka dapat disimpulkan bahwa:

1. Indikator bimbingan akademik berada pada kategori Baik terhadap efektifitas tugas dosen penasehat akademik dengan diberlakukanya sistem KRS Online yaitu $\mathbf{3 , 0 8}$.

2. Indikator bimbingan non akademik berada pada kategori Baik terhadap efektifitas tugas dosen penasehat akademik dengan diberlakukanya sistem KRS Online yaitu $\mathbf{3 , 1 0 .}$

3. Indikator memberikan bantuan untuk mencapai prestasi yang optimal kategori Baik terhadap efektifitas tugas dosen penasehat akademik dengan diberlakukanya sistem KRS Online yaitu 3.13.

\section{E. Saran}

1. Setelah melihat hasil kesimpulan di atas, saran yang bias disampaikan pada penelitian ini yaitu:

2. Bagi pimpinan UNP agar membuat peraturan khusus tentang dosen penasehat akademik,agar hubungan penasehat akademik dengan mahasiswa akan selalu terjalin dan peranan penasehat akademik dapat berjalan sebagaimana mestinya.

3. Bagi dosen penasehat akademik dapat membuat jadwal pertemuan berkala

4. dengan mahasiswa bimbinganya kareana hal ini akan berdampak kepada keberhasilan para mahasiswanya. 
5. Bagi mahasiswa harus selalu mejalin hubungan yang baik antara dosen Penasehat akademik karena dosen PA salah satu faktor keberhasilan studi mahasiswa di Perguruan Tinggi.

\section{Referensi}

Anas Sudijono. 2011. "Pengantar Evaluasi Pendidikan”. Jakarta: PT. Raja Grafindo Persada.

Riduwan. 2013. "Belajar Mudah Penelitian Untuk Guru Karyawan dan Peneliti Pemula". Bandung: Alfabeta.

Sugiyono. (2012). Metode Penelitian Kuantitatif Kualitatif dan $R \& D$. Bandung: CV. Alfabeta.

Suharsimi Arikunto. (2010). Prosedur Penelitian. Jakarta: Rieneka Cipta

Sugiyono. (2008). Metode Penelitian Kuantitatif Kualitatif dan R\&D. Bandung: Alfabeta.

Syamsul Arifin. (1997). Las Listrik dan Otogen. Jakarta: Ghalia Indonesia. 